EXTENDED REPORT

\title{
Impact of unilateral and bilateral vision loss on quality of life
}

\author{
H T V Vu, J E Keeffe, C A McCarty, H R Taylor
}

Br J Ophthalmol 2005;89:360-363. doi: 10.1136/bjo.2004.047498

See end of article for authors' affiliations

.....................

Correspondence to:

Hien T V Vu, Centre for Eye

Research Australia,

University of Melbourne,

32 Gisborne Street, East

Melbourne, Vicoria 3002,

Australia; hienv@unimelb.

edu.au

Accepted for publication 1 August 2004

\begin{abstract}
Aim: To investigate whether unilateral vision loss reduced any aspects of quality of life in comparison with normal vision and to compare its impact with that of bilateral vision loss.

Methods: This study used cluster stratified random sample of 3271 urban participants recruited between 1992 and 1994 for the Melbourne Visual Impairment Project. All predictors and outcomes were from the 5 year follow up examinations conducted in 1997-9.

Results: There were 2530 participants who attended the follow up survey and had measurement of presenting visual acuity. Both unilateral and bilateral vision loss were significantly associated with increased odds of having problems in visual functions including reading the telephone book, newspaper, watching television, and seeing faces. Non-correctable by refraction unilateral vision loss increased the odds of falling when away from home $(O R=2.86,95 \% \mathrm{Cl} 1.16$ to 7.08$)$, getting help with chores $(O R=3.09,95 \% \mathrm{Cl} 1.40$ to 6.83$)$, and becoming dependent (getting help with meals and chores) $(\mathrm{OR}=7.50,95 \% \mathrm{Cl} 1.97$ to 28.6$)$. Non-correctable bilateral visual loss was associated with many activities of daily living except falling.

Conclusions: Non-correctable unilateral vision loss was associated with issues of safety and independent living while non-correctable bilateral vision loss was associated with nursing home placement, emotional wellbeing, use of community services, and activities of daily living. Correctable or treatable vision loss should be detected and attended to.
\end{abstract}

$\mathrm{T}$ here has been an increasing interest in the effects of visual impairment on quality of life. Reduced visual acuity significantly reduces participation in social or religious activities, mobility, activities of daily living, and visually intensive tasks. ${ }^{1-4}$ In addition, reduced best corrected visual acuity in the better eye significantly increases the risk of having hip fracture, ${ }^{5}$ community and/or family support, ${ }^{6}$ nursing home placement, ${ }^{78}$ and low self rated health. ${ }^{9}$ It is also significantly associated with increased risk of mortality, ${ }^{10}$ any fractures, and two or more falls in the past year. ${ }^{8}$ Furthermore, the self reported impaired vision significantly increased the risk of being functionally impaired or having depressive symptoms in comparison with normal vision. ${ }^{11} \mathrm{~A}$ case-control study showed an increased risk of functional impairment or emotional distress associated with bilateral visual impairment. ${ }^{12}$

Thus, it has been recognised that bilateral vision loss reduces the quality and length of life. However, it has not been widely shown whether unilateral vision loss affects any aspects of quality of life. In comparison with people with normal vision, those with unilateral vision loss correctable by refraction did not have significantly poorer mean general health scores while those with non-correctable unilateral vision loss did have significantly poorer mean general health scores in the dimension of "role limitation due to physical problems." ${ }^{13}$ Furthermore, people with moderate to severe non-correctable unilateral vision loss had significantly poorer mean physical and emotional health scores in three dimensions: "role limitation due to physical problems," "social functioning," and "role limitation due to emotional problems."13

The Melbourne Visual Impairment Project is a population based study with comprehensive ophthalmological examinations. We explored the effect of unilateral vision loss on many aspects of life including safety and independent living, and compared this to bilateral vision loss.

\section{METHODS}

The detailed methodology for the baseline Melbourne VIP, a population based study of Melbourne adults, has been published previously. ${ }^{14}$ Briefly, nine pairs of census collector districts were randomly selected from the Melbourne Statistical Division. A household census was conducted to identify eligible residents who were aged 40 years and older and had been resident in their homes for at least 6 months. Eligible residents were then invited to local examination centres for a standard ophthalmic examination and completion of an extensive eye health related questionnaire. The protocol was approved by the human research and ethics committee of the Royal Victorian Eye and Ear Hospital, and all participants gave written, informed consent.

All participants who were still alive and could be contacted from the baseline survey were invited to participate in the 5 year follow up study..$^{10}$ This paper used data from the follow up study.

The standard ophthalmic examination included measurement of presenting (usual or "walking around") visual acuity from a logMAR chart, and visual field assessment using the Humphrey field analyser (Humphrey Instruments Inc) with 24-2 Fastpac statistical package. Best corrected visual acuity was measured after refraction for those with visual acuity less than 6/6. An eye had visual field loss if its visual field was classified as either homonymous hemianopia or having constriction of less than 20 radii of fixation. Vision loss was defined as either visual field loss or presenting visual acuity of less than 6/12. Vision loss in an eye was correctable if the eye had presenting visual acuity of $<6 / 12$, no visual field loss, and best corrected visual acuity of $\geqslant 6 / 12$. Moderate to severe non-correctable vision loss was defined as either best corrected visual acuity of less than $6 / 24$ or having visual field constriction of less than 10 radii of fixation. Thus, we considered correctable or non-correctable bilateral vision loss, and correctable, non-correctable, or moderate to severe 


\begin{tabular}{|c|c|c|c|}
\hline Risk factor $\left(\mathbf{n}^{*}\right)$ & Frequency $(\%)$ & Risk factor $\left(\mathrm{n}^{*}\right)$ & Frequency $(\%)$ \\
\hline Age (2530) & & Country of birth (2529) & \\
\hline $40-49$ & 322 (12.7) & Australia/New Zealand & $1468(58.1)$ \\
\hline $50-59$ & $763(30.2)$ & British Isles & $259(10.2)$ \\
\hline $60-69$ & $772(30.5)$ & Greece/Cyprus/Malta & $180(7.1)$ \\
\hline 70-79 & $497(19.6)$ & Italy & $241(9.5)$ \\
\hline $80+$ & $176(7.0)$ & Other & 381 (15.1) \\
\hline Female (2530) & $1383(54.7)$ & Duration of high blood pressure & 2352) \\
\hline Vision category (2530) & & None & $1478(62.8)$ \\
\hline Bilateral vision loss & $159(6.3)$ & $\leqslant 5$ years & $249(10.6)$ \\
\hline Unilateral vision loss & $302(11.9)$ & $6-10$ years & $189(8.0)$ \\
\hline Normal vision & $2069(81.8)$ & $>10$ years & $436(18.5)$ \\
\hline Smoking (2332) & & Arthritis (2338) & $828(35.4)$ \\
\hline Never & 1140 (48.9) & Diabetes (2411) & $193(8.0)$ \\
\hline Ex-smoker & 891 (38.2) & Gout (2331) & $228(9.8)$ \\
\hline Current & 301 (12.9) & Cardiovascular disease (2323) & $298(12.8)$ \\
\hline
\end{tabular}

non-correctable unilateral vision loss. The vision predictors were the variables indicating normal vision and one of the above five vision loss categories. In most cases these predictors had two levels: normal vision versus vision loss. However, we also divided non-correctable unilateral vision loss into two subcategories depending on whether the better eye had best corrected visual acuity of less than 6/7.5, and the corresponding vision predictor had three instead of two levels. Other predictors included age, sex, country of birth, smoking, duration of high blood pressure, arthritis, diabetes, gout, and cardiovascular disease (table 1). We examined 15 different outcomes obtained from the follow up survey (table 2), and some outcomes were obtained from the SF36 questionnaire used to assess general health related quality of life. ${ }^{15}$ The health habits interview included the outcomes of whether the participant did not feel full of life in the past month at all or had health/emotional problems that extremely interfered with normal social activities in the past month.

Interview data were entered directly into a Paradox database with built-in consistency checks. All other data were entered twice and verified. All statistical analyses were conducted with Statistical Analysis System (SAS version 8.2 for windows, SAS Institute, Cary, NY, USA). Separate analyses have been carried out for normal vision versus one of five different categories of vision loss. We first fitted the univariate logistic regressions for each outcome with age, sex, and vision loss as independent variables. A p value of less than 0.05 was considered to be statistically significant. We obtained the odds ratios of non-correctable univariate or bilateral vision loss versus normal vision from the best selected multivariate models by the backward stepwise regression method, where the initial models included 10 predictors obtained from the follow up survey for each outcome (table 1) - that is, we deleted the least significant factors other than age, sex, and vision loss until the $p$ values for the tests of whether they were different from zero were less than 0.05 .

\section{RESULTS}

There were 3040 (93\%) participants who were still alive out of 3271 participants in the baseline survey. Of 3040 remaining participants, $2594(85 \%)$ attended the follow up survey. Participation was not significantly related to visual outcomes such as decreased visual acuity, cataract, or glaucoma. In addition, it was not significantly related to sex even at the univariate level, and the p value was only 0.04 for age in the multivariate level. ${ }^{10}$ The only factors other than age related to participation was country of birth and language

Table 2 Frequencies of outcomes from the follow up survey for normal vision, unilateral, or bilateral loss

\begin{tabular}{|c|c|c|c|}
\hline Outcome description & Normal vision loss & $\begin{array}{l}\text { Unilateral vision } \\
\text { loss }\end{array}$ & Bilateral vision loss \\
\hline Fell at home in the past month & $63 / 1913$ (3.29\%) & $12 / 281(4.27 \%)$ & $7 / 132(5.3 \%)$ \\
\hline Fell when away from home in the past month & $40 / 1913$ (2.09\%) & $8 / 281(2.85 \%)$ & $3 / 133(2.26 \%)$ \\
\hline Ever fell in the past month & $99 / 1913(5.18 \%)$ & $19 / 281(6.76 \%)$ & $10 / 132(7.58 \%)$ \\
\hline Having hip replacement surgery & $32 / 1914(1.67 \%)$ & $10 / 280(3.57 \%)$ & $8 / 134(5.97 \%)$ \\
\hline $\begin{array}{l}\text { Living in a hostel, aged care hostel, } \\
\text { or nursing home }\end{array}$ & $6 / 1925(0.31 \%)$ & $5 / 281(1.78 \%)$ & $12 / 137(8.76 \%)$ \\
\hline $\begin{array}{l}\text { Using meals on wheels or supplied by } \\
\text { relatives or friends more than once per week }\end{array}$ & $17 / 1916(0.89 \%)$ & $10 / 281(3.56 \%)$ & $12 / 135(8.89 \%)$ \\
\hline $\begin{array}{l}\text { Getting help with chores from council } \\
\text { home help, relatives, or friends more } \\
\text { than once per week }\end{array}$ & $32 / 1916(1.67 \%)$ & $21 / 281(7.47 \%)$ & $15 / 135$ (11.1\%) \\
\hline $\begin{array}{l}\text { Dependency (getting help with meals and } \\
\text { chores) }\end{array}$ & $6 / 1916(0.31 \%)$ & $7 / 281(2.49 \%)$ & $8 / 135$ (5.93\%) \\
\hline $\begin{array}{l}\text { Health/emotional problems interfered } \\
\text { extremely with normal social activities in } \\
\text { the past month }\end{array}$ & $29 / 1938(1.5 \%)$ & $7 / 275(2.55 \%)$ & $9 / 123(7.32 \%)$ \\
\hline Did not feel full of life at all in the past month & $76 / 1883$ (4.04\%) & $10 / 268(3.73 \%)$ & $15 / 114(13.2 \%)$ \\
\hline Had problems reading the telephone book & $359 / 1910$ (18.8\%) & $77 / 278(27.7 \%)$ & $66 / 130(50.8 \%)$ \\
\hline Had problems reading newspaper & $218 / 1910$ (11.4\%) & $51 / 278(18.3 \%)$ & $52 / 131$ (39.7\%) \\
\hline Had problems watching television & $56 / 1914(2.93 \%)$ & $23 / 278(8.27 \%)$ & $35 / 134(26.1 \%)$ \\
\hline Had problems seeing faces & $18 / 1914(0.94 \%)$ & $12 / 278(4.32 \%)$ & $24 / 134(17.9 \%)$ \\
\hline Had problems doing other activities & $187 / 1914$ (9.77\%) & $30 / 277(10.8 \%)$ & $19 / 134$ (14.2\%) \\
\hline
\end{tabular}


Table 3 Univariate odds ratios $(95 \% \mathrm{Cl})$ adjusted by age and sex of correctable, non-correctable, or moderate to severe noncorrectable unilateral or bilateral vision loss versus normal vision

\begin{tabular}{|c|c|c|c|c|c|}
\hline \multirow[b]{2}{*}{ Outcome (short description) } & \multicolumn{3}{|l|}{ Unilateral vision loss } & \multicolumn{2}{|l|}{ Bilateral vision loss } \\
\hline & Correctable & Non-correctable & $\begin{array}{l}\text { Moderate to severe } \\
\text { non-correctable }\end{array}$ & Correctable & Non-correctable \\
\hline Fell at home & $1.06(0.47$ to 2.40$)$ & $0.71(0.26$ to 1.93$)$ & $0.84(0.24$ to 2.98$)$ & $0.45(0.10$ to 1.96$)$ & $1.07(0.37$ to 3.10$)$ \\
\hline Fell when away & 0.61 (0.15 to 2.58 ) & 2.86 (1.16 to 7.08$)$ & $1.92(0.44$ to 8.29$)$ & $1.45(0.33$ to 6.32$)$ & $0.98(0.12$ to 7.70$)$ \\
\hline Ever fell & $0.94(0.46$ to 1.92$)$ & $1.25(0.6$ to 2.59$)$ & $1.19(0.44$ to 3.23$)$ & $0.74(0.25$ to 2.14$)$ & $1.12(0.43$ to 2.92$)$ \\
\hline Hip replacement surgery & $0.93(0.31$ to 2.76$)$ & $1.30(0.48$ to 3.51$)$ & $1.65(0.50$ to 5.45$)$ & $0.67(0.15$ to 3.04$)$ & $1.76(0.62$ to 5.00$)$ \\
\hline Nursing home placement & $1.20(0.14$ to 10.7$)$ & $2.92(0.67$ to 12.8$)$ & $3.24(0.52$ to 20.2$)$ & $4.14(0.67$ to 25.5$)$ & 14.8 (4.13 to 53.1$)$ \\
\hline Using supplied meals & $1.07(0.30$ to 3.83$)$ & $2.29(0.83$ to 6.33$)$ & $2.51(0.71$ to 8.90$)$ & $0.42(0.05$ to 3.39$)$ & 5.21 (2.07 to 13.1$)$ \\
\hline Getting help with chores & $1.49(0.62$ to 3.56$)$ & 2.90 (1.35 to 6.24$)$ & 3.01 (1.09 to 8.27$)$ & $1.22(0.39$ to 3.77$)$ & 2.95 (1.26 to 6.92$)$ \\
\hline Dependency & $1.05(0.12$ to 9.43$)$ & $6.90(1.80$ to 26.4$)$ & $6.71(1.50$ to 30.0$)$ & N/A & $9.48(2.52$ to 35.7$)$ \\
\hline Health/emotional problems & $0.77(0.18$ to 3.30$)$ & $2.33(0.81$ to 6.69$)$ & $1.93(0.41$ to 9.14$)$ & $1.85(0.41$ to 8.36$)$ & $5.81(2.08$ to 16.2$)$ \\
\hline Did not feel full of life & $0.80(0.34$ to 1.90$)$ & $0.57(0.19$ to 1.67$)$ & $0.91(0.26$ to 3.22$)$ & $0.82(0.24$ to 2.79$)$ & $4.63(2.18$ to 9.82$)$ \\
\hline Reading the telephone book & $1.15(0.77$ to 1.72$)$ & $2.26(1.50$ to 3.40$)$ & $2.13(1.20$ to 3.79$)$ & 2.96 (1.79 to 4.90$)$ & 6.41 (3.59 to 11.5$)$ \\
\hline Reading newspaper & $1.19(0.73$ to 1.93$)$ & 2.36 (1.49 to 3.75$)$ & 2.85 (1.55 to 5.26$)$ & 2.50 (1.41 to 4.45$)$ & $9.97(5.51$ to 18.0$)$ \\
\hline Watching television & 2.98 (1.57 to 5.66$)$ & 2.30 (1.07 to 4.94$)$ & $2.51(0.90$ to 6.98$)$ & 7.89 (3.91 to 15.9$)$ & $12.5(6.17$ to 25.4$)$ \\
\hline Seeing faces & $2.81(0.92$ to 8.57$)$ & $5.43(2.04$ to 14.5$)$ & $6.70(2.04$ to 22.0$)$ & $9.05(2.91$ to 28.1$)$ & 40.9 (16.8 to 99.2$)$ \\
\hline Doing other activities & $1.25(0.74$ to 2.14$)$ & $1.28(0.69$ to 2.38$)$ & $0.78(0.27$ to 2.21$)$ & $0.84(0.33$ to 2.14$)$ & $3.45(1.72$ to 6.94$)$ \\
\hline
\end{tabular}

spoken at home, where non-English speakers and people born in Greece, Malta, or Cyprus were significantly less likely to participate. ${ }^{10}$ However, the rates of participation based on those who were still alive at the follow up survey were $73 \%$ for non-English speakers, 84\% for English speakers, $72 \%$ for people born in Greece, Malta, or Cyprus, and 79\% for people born in other places. The effects of reduced best corrected visual acuity in the better eye on deaths and falls in the Melbourne VIP project have been previously examined, ${ }^{10} 16$ where the predictors were from the baseline survey.

Of 2594 participants who attended the follow up survey, 2530 (98\%) had complete data records for presenting visual acuity. Of 159 participants with bilateral vision loss, 84 (53\%) had correctable vision loss and 75 (47\%) had non-correctable vision loss. Of 302 participants with unilateral vision loss, 165 (55\%) had correctable vision loss and 137 (45\%) had noncorrectable vision loss. Also $64(47 \%)$ of 137 with noncorrectable unilateral vision loss had best corrected visual acuity of less than $6 / 7.5$ in the better eye. It should be noted that the frequency of an outcome was reported only for those who had a complete record for that outcome (tables 1 and 2). For example, only 137 (78\%) of 159 participants with bilateral vision loss had a complete record for the outcome of nursing home placement. Similarly, 281 (93\%) of 302 participants with bilateral vision loss had a complete record for the outcome of getting help with chores.

For all outcomes we included only age, sex, and vision loss in the univariate analyses, and we further selected other significant predictors by the backward selection method in addition to these predictors. From the univariate analyses, both correctable bilateral or unilateral vision loss were not significantly associated with any outcomes except those of visual functions (table 3). Moderate to severe non-correctable unilateral vision loss did not produce more significant results than non-correctable unilateral vision loss. Thus we carried out the multivariate analyses for only non-correctable unilateral and bilateral vision loss. Non-correctable vision loss remained significant or insignificant in the best selected multivariate models as they were in the corresponding univariate models for all outcomes, and the magnitudes of the odds ratios from the best selected multivariate models were essentially the same as those from the univariate models.

We presented the univariate and multivariate odds of vision loss verus normal vision (tables 3 and 4). Noncorrectable unilateral vision loss was associated with vision related activities, falling, and dependency issues. Noncorrectable unilateral vision loss with best corrected visual

Table 4 Odds ratios $(95 \% \mathrm{Cl})$ of non-correctable unilateral or bilateral vision loss versus normal vision from the best selected multivariate models (all analyses include age and sex)

\begin{tabular}{|c|c|c|c|}
\hline Outcome (short description) & $\begin{array}{l}\text { Other factors in the best selected multivariate } \\
\text { models }\end{array}$ & Unilateral vision loss & Bilateral vision loss \\
\hline Fell at home & & $0.71(0.26$ to 1.93$)$ & $1.07(0.37$ to 3.10$)$ \\
\hline Fell when away & & 2.86 (1.16 to 7.08$)$ & $0.98(0.12$ to 7.70$)$ \\
\hline Ever fell & Arthritis $†$ & $1.25(0.6$ to 2.59$)$ & $1.02(0.39$ to 2.67$)$ \\
\hline Hip replacement surgery & Arthritis, cardiovascular disease to country of birth & $1.80(0.61$ to 5.28$)$ & $1.50(0.50$ to 4.52$)$ \\
\hline Nursing home placement & & $2.92(0.67$ to 12.8$)$ & 14.8 (4.13 to 53.1$)$ \\
\hline Using supplied meals & Gout*, arthritis†, smoke $\dagger$ & $2.44(0.85$ to 6.98$)$ & 4.40 (1.74 to 11.2 ) \\
\hline Getting help with chores & Arthritis*, duration of high blood pressure, smoking ${ }^{*}$ & 3.09 (1.40 to 6.83 ) & $3.19(1.34$ to 7.55$)$ \\
\hline Dependency & Gout*, duration of high blood pressure $\dagger$ & 7.50 (1.97 to 28.6$)$ & $11.8(3.16$ to 44.2$)$ \\
\hline Health/emotional problems & Arthritis & 2.74 (0.93 to 8.07$)$ & $6.28(2.16$ to 18.2$)$ \\
\hline Did not feel full of life & Arthritis, cardiovascular disease & $0.64(0.22$ to 1.89$)$ & 4.17 (1.87 to 9.32$)$ \\
\hline Reading the telephone book & Arthritis & 2.21 (1.46 to 3.33 ) & 6.50 (3.59 to 11.7$)$ \\
\hline Reading newspaper & & 2.36 (1.49 to 3.75$)$ & $9.97(5.51$ to 18.0$)$ \\
\hline Watching television & Arthritis & 2.29 (1.06 to 4.92$)$ & $12.0(5.81$ to 24.7$)$ \\
\hline Seeing faces & & $5.43(2.04$ to 14.5$)$ & 40.9 (16.8 to 99.2$)$ \\
\hline Doing other activities & Cardiovascular disease $†$ & $1.28(0.69$ to 2.38$)$ & 3.57 (1.74 to 7.32$)$ \\
\hline
\end{tabular}


acuity of less than 6/7.5 in the better eye increased the odds of having health/emotional problems in comparison with normal vision (univariate $\mathrm{OR}=4.94,95 \% \mathrm{CI} 1.13$ to 21.6 ). On the other hand, non-correctable bilateral visual loss was not associated with falling, but it was associated with dependency, nursing home placement, emotional wellbeing, and visual tasks. Non-correctable unilateral vision loss gave a twofold to fivefold increase in the odds of having problems in reading the telephone book, reading the newspaper, watching television, and seeing faces. Non-correctable bilateral vision loss gave a sixfold to 41 -fold increase in the odds of having these problems.

\section{DISCUSSION}

Even non-correctable unilateral vision loss had a measurable impact on falling and some other activities of independent living, although its impact was less than that of bilateral vision loss. Both non-correctable unilateral and bilateral vision loss was significantly associated with increased odds of having problems in many activities of daily life.

Non-correctable unilateral vision loss was associated with increased odds of falling when away from home although not of having hip replacement surgery. On the other hand, the falls in those with bilateral vision loss may result in more severe consequences such as death or having hip replacement surgery. Thus, of those who fell, those with bilateral vision loss were less likely to attend the survey than those with unilateral vision loss. This may explain why we could not detect significant association between falling and noncorrectable bilateral vision loss in our study.

The univariate odds ratios showed no significant associations between correctable unilateral vision loss with any outcomes except those of visual functions. This conclusion agreed with that from the BMES. ${ }^{13}$ However, of those with unilateral vision loss, the level of severity in the worse eye did not really affect aspects of independent living in our study (table 3). On the contrary, those with moderate to severe non-correctable unilateral vision loss had significantly poorer general health scores than those with normal vision in the dimensions of "social functioning" and "role limitation due to emotional problems" while those with non-correctable unilateral vision loss did not in the BMES. ${ }^{13}$

The study has a number of strengths, including its population based, prospective design, and its use of a comprehensive ophthalmological examination at each time point. Although multiple comparisons were made, they were explicitly stated, planned, and for the most part quite strong and consistent. The study had a number of limitations, including the possible selection biases as a result of loss of follow up, the cross sectional design, and each outcome had about $8 \%$ of missing data records. We concluded that noncorrectable unilateral vision loss may cause some significant problems in activities dependent on vision including issues of safety and dependent living, and people with non-correctable unilateral vision loss may need assistance in these areas.

\section{ACKNOWLEDGEMENTS}

The Melbourne Visual Impairment Project was supported, in part, by grants from National Health and Medical Research Council, Canberra, Australia; Victorian Health Promotion Foundation; Jack Brockhoff Foundation, Melbourne, Australia; Edols Bequest; Ansell Ophthalmology Foundation, Melbourne, Australia; Eye, Ear, Nose and Throat Research Institute; Appel Family Bequest; Hugh Williamson Foundation and Ian Potter Foundation. Associate professor Keeffe is the recipient of the Wagstaff Fellowship in Ophthalmology from the Royal Victorian Eye and Ear Hospital.

\section{Authors' affiliations}

H T V Vu, J E Keeffe, H R Taylor, Centre for Eye Research Australia, University of Melbourne, 32 Gisborne Street, East Melbourne, Vic 3002, Australia

C A McCarty, Marshfield Clinic Research Foundation, 1000 North Oak Avenue (ML1), Marshfield WI 54449, USA

Competing interests: None declared.

Ethical approval: The protocol was approved by the Human Research and Ethics Committee of the Royal Victorian Eye and Ear Hospital.

\section{REFERENCES}

1 West SK, Rubin GS, Broman AT, et al. How does visual impairment affect performance on tasks of everyday life? The SEE project. Arch Ophthalmol 2002;120:774-80.

2 West SK, Munoz B, Rubin GS, et al. Function and visual impairment in a population-based study of older adults. The SEE project. Invest Ophthalmol Vis Sci 1997;38:72-82.

3 Weih LM, Hassell JB, Keeffe J. Assessment of the impact of vision impairment. Invest Ophthalmol Vis Sci 2002;43:927-35.

4 Lamoureux EL, Hassell JB, Keeffe JE. The determinants of participation in activities of daily living in people with impaired vision. Am J Ophthalmol 2004; 137:265-70.

5 Ivers RQ, Cumming RG, Mitchell $P$, et al. Visual risk factors for hip fracture in older people. J Am Geriatr Soc 2003;51:356-63.

6 Wang JJ, Mitchell P, Smith W, et al. Impact of visual impairment on use of community support services by elderly persons: the Blue Mountains Eye Study. Invest Ophthalmol Vis Sci 1999;40:12-19.

7 Wang JJ, Mitchell P, Cumming RG, et al. Visual impairment and nursing home placement in older Australians: the Blue Mountains Eye Study. Ophthalmic Epidemol 2003;10:3-13.

8 Klein BEK, Moss SE, Klein R, et al. Associations of visual function with physical outcomes and limitations 5 years later in an older population. The Beaver Dam Eye Study. Ophthalmology 2003; 1 10:644-50.

9 Wang JJ, Mitchell P, Smith W. Vision and low self-rated health: the Blue Mountains Eye Study. Invest Ophthalmol Vis Sci 2001;41:49-54.

10 McCarty CA, Nanjan MB, Taylor H. Visual impairment predicts 5 year mortality. Br J Ophthalmol 2001;85:322-6.

11 Rovner BW, Ganguli M. Depression and disability associated with impaired vision: the MoVies Project. J Am Geriatr Soc 1998;46:617-19.

12 Scott IU, Shein OD, Fever WJ, et al. Emotional distress in patients with retinal disease. Am J Ophthalmol 2001;131:584-9.

13 Chia EM, Mitchell $P$, Rochtchina E, et al. Unilateral visual impairment and health related quality of life: the Blue Mountains Eye Study. Br J Ophthalmol 2003;87:392-5.

14 Livingston PM, Carson CA, Stanislavsky YL, et al. Methods for a populationbased study of eye disease: the Melbourne Visual Impairment Project. Ophthalmol Epidemiol 1994;1:139-48.

15 Ware JE. How to score the revised MOS Short-Form Health Scale (SF-36). Boston, MA: The Health Institute, New England Medical Center Hospitals, 1988.

16 McCarty CA, Fu CL, Taylor HR. Predictors of falls in the Melbourne visual impairment project. Aust N Z J Public Health 2002;26:116-19. 